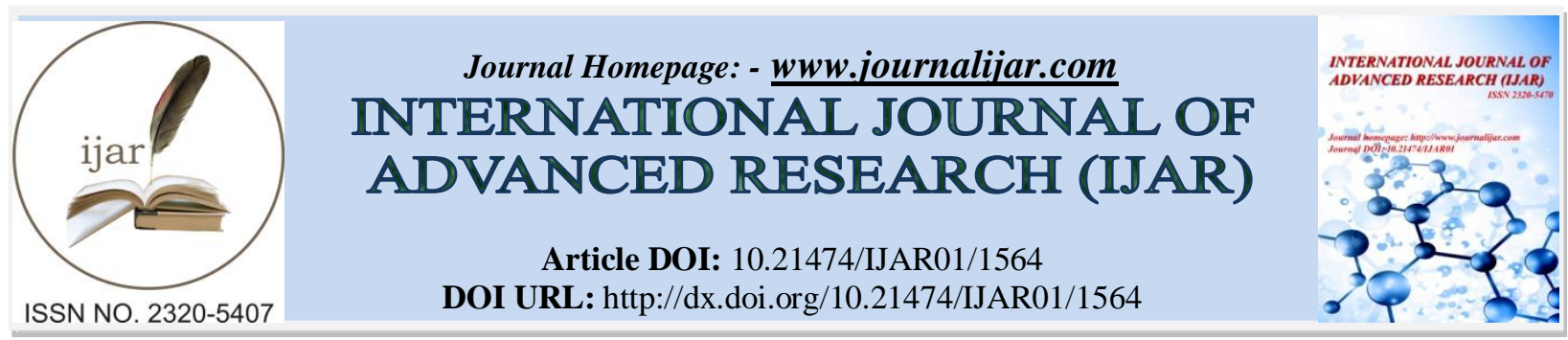

RESEARCH ARTICLE

\title{
BREAST MASS MANAGEMENT; AN INTERVENTIONAL STUDY.
}

\author{
Dr. Luai Farhan Zghair (M.B.Ch.B, D.G.S, F.I.C.M.S, C.A.B.S) ${ }^{1}$, Dr. Qasim Hamza Eriby (M.B.Ch.B, \\ F.I.C.M.S, C.A.B.S) ${ }^{2}$ and Dr. Jamal Abed Hasan(M.B.Ch.B, C.A.B $)^{2}$. \\ 1. Senior and Assist Prof in general surgery at Medical College, AL- Iraqia University, Iraq, Baghdad. \\ 2. Senior in General Surgery at AL Yarmouk Teaching Hospital, Iraq, Baghdad.
}

\section{Manuscript Info}

\section{Manuscript History}

Received: 12 July 2016

Final Accepted: 16 August 2016

Published: September 2016

Key words:-

Breast, breast mass, breast lump.

\section{Abstract}

Background:- The breasts are present in both sexes and have similar characteristics until puberty when, in the female, they enlarge and develop the capacity for milk production. The breasts are essentially specialized skin glands comprising fat, glandular and connective tissue. The protuberant part of the human breast is generally described as overlying the second to the sixth ribs and extending from the lateral border of the sternum to the anterior axillary line. A dominant breast mass requires histologic diagnosis. The management of a solid mass depends on the degree of clinical suspicion and the patient's age.

Objective:- The aim of the study is diagnose the causes of the breast mass and the management of this problem.

Patients and methods:- This is an interventional study on 100 patients with breast mass with or without breast pain or nipple discharge or gynecomastia from the period of June 2015 to July 2016. All patients completed a questionnaire including age, sex, occupation, residence, present symptoms and duration, previous medical and drugs history, previous surgical history, social history and family history. Clinical and physical examination were done to all patients. Completed all investigation including laboratory and radiological investigation, ultrasound, CT scan, and MRI accordingly. Incisional or excisional biopsy were done to all patients, with or without Fine needle aspiration cytology before it.

Results:- One hundred patients were studied, 97 female (97\%) and 3 male $(3 \%)$. The female to male ratio was $32.33: 1$. The age ranged from 11 to 90 years, with a mean age 40 years \pm 5 years. The majority being in the $4^{\text {th }}$ decade of life, constituting 24 patient $(24 \%)$. Also the study showed that the causes of the breast mass are fibroadenosis 28 patients (28\%), the next was fibroadenoma 19 patients (19\%), followed by breast cancer 15 patients $(15 \%)$, breast abscess 5 patients $(5 \%)$, ductectesia 5 patients $(5 \%)$, fat necrosis 5 patients $(5 \%)$, chronic mastitis 5 patients $(5 \%)$, intraductal papilloma 5 patients $(5 \%)$, galactocele 4 patients (4\%), lipoma 4 patients (4\%), gynecomastia 3 patients $(3 \%)$, granuolomatous mastitis one patient $(1 \%)$, and phyllodes tumour one patient $(1 \%)$.

Conclusion:- Breast mass is a common universal condition in clinical practice and remain a major medical and surgical problem and need 
good assessment to the patients to detect the malignant breast disease as soon as possible in the early stage and treated the condition before local or general metastases occurs.

Copy Right, IJAR, 2016,. All rights reserved.

\section{Introduction:-}

The breasts are present in both sexes and have similar characteristics until puberty when, in the female, they enlarge and develop the capacity for milk production. ${ }^{(1)}$ The breasts are essentially specialized skin glands comprising fat, glandular and connective tissue. ${ }^{(1)}$ The protuberant part of the human breast is generally described as overlying the second to the sixth ribs and extending from the lateral border of the sternum to the anterior axillary line. ${ }^{(2)}$ Actually, a thin layer of mammary tissue extends considerably further, from the clavicle above to the seventh or eighth ribs below and from the midline to the edge of the latissimus dorsi posteriorly. ${ }^{(2)}$ The breast is modified sweat glnd. ${ }^{(3)}$ Its derived from ectoderm. ${ }^{(4)}$ In the 5th-6th week of fetal life, breast development begins when epidermal cells invaginate toward the deeper mesenchyme and form the primary mammary ridges or milk lines. These ridges extend from the axilla to the groin, but, normally, the cranial and caudal portions involute, which leaves only the portion at the fourth intercostal space to develop into the breast. ${ }^{(5)}$ In prepubertal children, the breasts are composed of epithelial-lined ducts surrounded by a connective tissue stroma. ${ }^{(5,6)}$ These ducts are often enlarged at birth in both male and female full-term infants because of the effects of maternal hormones. Bilateral subareolar palpable nodules are common and may persist for the first 6-12 months of life. ${ }^{(6,7)}$ In girls, a second phase of breast development begins at puberty. The onset of pubertal breast development is called the larche, which normally occurs after age 89 years and before 13 years of age. ${ }^{(5)}$ Under the influence of estrogen, progesterone, and other hormones, the ducts begin to elongate and branch, leading to lobular differentiation and the development of terminal duct-lobular units. ${ }^{(8)}$ Pubertal breast development is divided into five phases called Tanner stages. ${ }^{(5)}$ Upon completion of this process, the mature female breast is composed of fatty tissue and glandular elements supported by a framework of fibrous connective tissue (Cooper ligaments). Gynecomastia is excessive development of the male breast and clinically manifests as tender, firm subareolar nodules. In children, gynecomastia often occurs during the neonatal period and puberty. Bilateral enlargement of the breasts is common in neonates because of the influence of maternal hormones. At puberty, two-thirds to three-fourths of boys have some degree of breast enlargement, which peaks at age 13-14 years and usually resolves within 2 years. ${ }^{(5,9)}$ The condition is usually bilateral but may be unilateral, and it may be familial. The etiology of gynecomastia is thought to be a decrease in the ratio of testosterone to estrogen. Excessive body fat may lead to increased conversion of testosterone to estrogen. Excessive gynecomastia or development of gynecomastia in a prepubertal boy suggests the presence of an endocrinopathy or other underlying disease. Uncommon causes of gynecomastia include estrogen-producing tumors of the testis, such as Sertoli or Leydig cell tumors; rare, feminizing adrenal cortical tumors; gonadotropin-secreting tumors, such as hepatoblastoma and fibrolamellar carcinoma or choriocarcinoma; prolactinomas; liver disease; Klinefelter syndrome; testicular feminization syndrome; and neurofibromatosis type 1. In addition, use of drugs such as marijuana, anabolic steroids, corticosteroids, cimetidine, digitalis, and tricyclic antidepressants can cause male breast development. ${ }^{(5)}$ Juvenile hypertrophy, which is also known as virginal hypertrophy or macromastia, is excessive female breast enlargement that occurs in a relatively short period of weeks to months. Juvenile hypertrophy often begins shortly after menarche but may occur during pregnancy. Usually both breasts are symmetrically, diffusely enlarged, but the condition may be asymmetric or even unilateral. The pathologic appearance of juvenile hypertrophy shares features with gynecomastia. There is no discrete mass, and the cut surface of lesions appears homogeneous grayish tan to yellow. Histologic evaluation reveals an irregular distribution of ducts, with varying degrees of cystic dilatation and intraductal hyperplasia within a dense hypocellular stroma. No lobular units are seen in the areas of hypertrophy. ${ }^{(6,7)}$ Patients are often very symptomatic, but surgery should be avoided in girls with ongoing breast growth. These patients are generally treated with anti-estrogen agents, such as tamoxifen. After growth has stabilized, surgical options include reduction mammoplasty and mastectomy with reconstruction. ${ }^{(10)}$ The breast is one of the common sites of cancer in women, it is also the site of different types of benign tumors and may be subject to acute inflammation and abscess formation. ${ }^{(1)}$ The most common breast problems for which women consult a physician are breast pain, nipple discharge and a palpable mass. Most women with these complaints have benign breast disease. Breast pain alone is rarely a presenting symptom of cancer, and imaging studies should be reserved for use in women who fall within usual screening guidelines. A nipple discharge can be characterized as physiologic or pathologic based on the findings of the history and physical examination. A pathologic discharge is an indication for terminal duct excision. A dominant breast mass requires histologic diagnosis. A breast cyst can be diagnosed and 
treated by aspiration. The management of a solid mass depends on the degree of clinical suspicion and the patient's age. $^{(12)}$

\section{Objective:-}

The aim of the study is diagnose the causes of the breast mass and the management of this problem.

\section{Patients and methods:-}

This is an interventional study on 100 patients with breast mass with or without breast pain or nipple discharge or gynecomastia from the period of June 2015 to July 2016. All patients completed a questionnaire including age, sex, occupation, residence, present symptoms and duration, previous medical and drugs history, previous surgical history, social history and family history. Clinical and physical examination were done to all patients. Completed all investigation including laboratory and radiological investigation, ultrasound, CT scan, and MRI accordingly. Incisional or excisional biopsy were done to all patients, with or without fine needl aspiration cytology before the incisional or excisional biopsy.

\section{Results:-}

One hundred patients were studied, 97 female (97\%) and 3 male (3\%) as shown in Table 1.The female to male ratio was 32.33:1. The age ranged from 11 to 90 years, with a mean age 40 years \pm 5 years. The majority being in the $4^{\text {th }}$ decade of life, constituting 24 patient (24\%) as shown in Table 1 . Also the study showed that the causes of the breast mass are fibroadenosis 28 patients (28\%), the next was fibroadenoma 19 patients (19\%), followed by breast cancer 15 patients $(15 \%)$, breast abscess 5 patients (5\%), ductectesia 5 patients $(5 \%)$, fat necrosis 5 patients $(5 \%)$, chronic mastitis 5 patients (5\%), intraductal papilloma 5 patients (5\%), galactocele 4 patients (4\%), lipoma 4 patients (4\%), gynecomastia 3 patients (3\%), granuolomatous mastitis one patient (1\%), and phyllodes tumour one patient $(1 \%)$, as shown in Table 2 .

Table 1:- Age \& Sex distribution of breast mass in patients.

\begin{tabular}{|l|l|l|l|l|}
\hline Age group (Years) & No of male & No of female & Total & \% \\
\hline $\mathbf{1 1 - 2 0}$ & 0 & 12 & 12 & 12 \\
\hline $\mathbf{2 1}-\mathbf{3 0}$ & 2 & 12 & 14 & 14 \\
\hline $\mathbf{3 1}-\mathbf{4 0}$ & 1 & 23 & 24 & 24 \\
\hline $\mathbf{4 1 - 5 0}$ & 0 & 22 & 22 & 22 \\
\hline $\mathbf{5 1 - 6 0}$ & 0 & 16 & 16 & 16 \\
\hline $\mathbf{6 1 - 7 0}$ & 0 & 6 & 6 & 6 \\
\hline $\mathbf{7 1 - 8 0}$ & 0 & 4 & 4 & 4 \\
\hline $\mathbf{8 1 - 9 0}$ & 0 & 2 & 2 & 2 \\
\hline Total & 3 & 97 & 100 & $100 \%$ \\
\hline
\end{tabular}

Table 2:- Causes of breast mass.

\begin{tabular}{|l|l|l|}
\hline Causes of breast mass & No of patients & \% \\
\hline Fibroadenosis & 28 & 28 \\
\hline Fibroadenoma & 19 & 19 \\
\hline Breast cancer & 15 & 15 \\
\hline Breast abscess & 5 & 5 \\
\hline Ductectesia & 5 & 5 \\
\hline Fat necrosis & 5 & 5 \\
\hline Chronic mastitis & 5 & 5 \\
\hline Intraductal papilloma & 5 & 5 \\
\hline Galactocele & 4 & 4 \\
\hline Lipoma & 4 & 4 \\
\hline Gynecomastia & 3 & 3 \\
\hline Granuolomatous mastitis & 1 & 1 \\
\hline Phyllodes tumour & 1 & 1 \\
\hline Total & 100 & 100 \\
\hline
\end{tabular}




\section{Discussion:-}

Determining what constitutes a dominant mass is often difficult, particularly in pre-menopausal women, the normal glandular tissue of the breast is nodular, and this nodularity is usually most pronounced in the upper outer quadrant of the breast and the area of the inframammary ridge, nodularity particularly when it waxes and wanes during the menstrual cycle is a physiologic process and is not an indication of breast pathology, dominant masses are characterized by persistence throughout the menstrual cycle, these masses may be discrete or poorly defined, but they differ in character from the surrounding breast tissue and the corresponding area in the contralateral breast. ${ }^{(12)}$ Cysts are a common cause of dominant breast masses in premenopausal women more than 40 years of age but an infrequent cause of such masses in younger women. ${ }^{(12)}$ In one study, cysts accounted for only 10 percent of breast masses in women less than 40 years of age. ${ }^{(13)}$ Although cysts may occur at any age, they are relatively uncommon in postmenopausal women who are not taking hormones. ${ }^{(12)}$ Cysts often fluctuate with the menstrual cycle and are particularly common during periods of hormonal irregularity, clinically cysts are usually well demarcated from the surrounding breast tissue, they are characteristically firm and mobile, cysts that have filled rapidly may be tender. ${ }^{(12)}$ On physical examination, it is often difficult to distinguish a cyst from a solid mass, Ultrasonography or aspiration must be used to establish a definitive diagnosis, cysts require surgical biopsy only if the aspirated fluid is bloody, the palpable abnormality does not resolve completely after the aspiration of fluid or the same cyst recurs multiple times in a short period of time. ${ }^{(12)}$ In one follow-up study, cytologic examination found atypical cells in 1,677 of 6,782 cyst fluid aspirates. No cancers were identified. ${ }^{(14)}$ Routine cytologic examination of cyst fluid is not cost-effective, often results in unnecessary surgical biopsies and does not obviate the need for clinical follow-up. ${ }^{(12)}$ Patients with a solitary breast cyst should be reexamined four to six weeks after cyst aspiration to determine if the cyst has recurred. ${ }^{(12)}$ One follow-up study of 389 women who underwent cyst aspiration found that 44 women had a recurrent cyst and 20 had a solid mass at the aspiration site. In biopsies of the 20 solid masses, two cancers were found. ${ }^{(15)}$ Aspiration is still an appropriate first step in the management of a breast cyst, but clinical follow-up after aspiration is essential. ${ }^{(12)}$ Noncystic masses in premenopausal women that are clearly different from the surrounding breast tissue require histologic sampling by fine-needle aspiration, core cutting needle biopsy or excisional biopsy. ${ }^{(12)}$ The extent of imaging required for the evaluation of a solid breast mass depends on the age and risk status of the patient and the degree of clinical suspicion, Imaging studies are used to define the extent of a potential malignancy and to identify non palpable masses elsewhere in the breast, findings that may influence the choice of local therapy. ${ }^{(12)}$ The decision to perform a biopsy is based on the clinical determination that a dominant mass is present, not on the findings of imaging studies, because of the known false-negative rate of mammography (approximately 10 to 20 percent). ${ }^{(16)}$ As patient age increases, clinically evident benign breast problems become less frequent, therefore, abnormalities detected on physical examination in older women should be regarded as possible cancers until they are documented to be benign. ${ }^{(12)}$

In women more than 40 years of age, diagnostic mammography is a standard part of the evaluation of a solid breast mass. In the patient with a breast complaint, a screening study consisting of two standard views of the breast (craniocaudal and mediolateral oblique) is inappropriate. The radiologist should be notified of the area of clinical concern so that it can be defined with a radiopaque marker to ensure that any noted mammographic abnormalities correspond to the clinical finding. Extra views can be obtained to ensure that the lesion is adequately visualized. ${ }^{(17)}$ The purpose of this evaluation is to document the extent of the mass and the presence of other lesions within the breast that might influence the patient's suitability for breast-conserving surgery if cancer is diagnosed. ${ }^{(18)}$ In the presence of a dominant breast mass, a normal mammogram should never be considered proof of the absence of breast cancer, even in modern series, 9 to 22 percent of palpable breast cancers are not seen on mammograms. ${ }^{(16,19,20)}$ In our research one hundred patients were studied, 97 female $(97 \%)$ and 3 male $(3 \%)$. The female to male ratio was 32.33:1.The age ranged from 11 to 90 years, with a mean age 40 years \pm 5 years. The majority being in the $4^{\text {th }}$ decade of life, constituting 24 patient (24\%). Completed all investigation including laboratory and radiological investigation, ultrasound, CT scan, and MRI accordingly. Incisional or excisional biopsy were done to all patients, with or without Fine needle aspiration cytology before it. The study showed that the causes of the breast mass are fibroadenosis 28 patients $(28 \%)$, the next was fibroadenoma 19 patients $(19 \%)$, followed by breast cancer 15 patients $(15 \%)$, breast abscess 5 patients $(5 \%)$, ductectesia 5 patients $(5 \%)$, fat necrosis 5 patients $(5 \%)$, chronic mastitis 5 patients $(5 \%)$, intraductal papilloma 5 patients $(5 \%)$, galactocele 4 patients $(4 \%)$, lipoma 4 patients $(4 \%)$, gynecomastia 3 patients (3\%), granuolomatous mastitis one patient (1\%), and phyllodes tumour one patient(1\%). The 3 patients male (3\%) with gynecomastia, bilateral mammoplasty were done to them and they are in a good condition. According to the 15 patients (15\%) with breast cancer, all are female, 11 patients (11\%) of them have unilateral invasive ductal carcinoma, modified radical mastectomy with axillary nods clearance were done to all, and after surgery they are send to oncology department to complete their treatment. The other 3 patients (3\%) have 
inflammatory carcinamatosis and thy are old age patients and are refuse all type of treatment. And the last patient (1\%) have bilateral lobular carcinoma so bilateral modified radical mastectomy with bilateral axillary nods clearance was done to here. Other patients are treated according to her condition either by complete excision of the mass or cyst or drainage of the abscess. In second study of 52 patients showed that the most common cause of breast mass are malignant and followed by fibroadenoma. ${ }^{(21)}$ as shown in Table 3. In third study of 42 patients showed that the most common cause of breast mass are fibroadenoma followed by fibroadenosis. ${ }^{(22)}$ as shown in Table 3.

Table 3:- Causes of breast mass.

\begin{tabular}{|l|l|l|l|}
\hline Causes of breast mass & Our study & Second study $^{(21)}$ & Third study $^{(22)}$ \\
\hline Fibroadenosis & 28 & 1 & 9 \\
\hline Fibroadenoma & 19 & 10 & 15 \\
\hline Breast cancer & 15 & 29 & \\
\hline Breast abscess & 5 & 1 & 1 \\
\hline Ductectesia & 5 & & \\
\hline Fat necrosis & 5 & & 3 \\
\hline $\begin{array}{l}\text { Chronic mastitis, (plasma cell mastitis), ( } \\
\text { benign lesion), (mastopathy) }\end{array}$ & 5 & 9 & 7 \\
\hline Intraductal papilloma & 5 & 1 & 1 \\
\hline Galactocele & 4 & & \\
\hline Lipoma & 4 & & 2 \\
\hline Gynecomastia & 3 & & 2 \\
\hline Granuolomatous mastitis & 1 & & 1 \\
\hline Phyllodes tumour & 1 & & \\
\hline Sclerosing mastopathy & \multicolumn{2}{l|}{} \\
\hline Benign lymph nod & & 1 & 1 \\
\hline Total & 100 & 52 & 42 \\
\hline
\end{tabular}

\section{Conclusion:-}

Breast mass is a common universal condition in clinical practice and remain a major medical and surgical problem and need good assessment to the patients to detect the malignant breast disease as soon as possible in the early stage and treated the condition before local or general metastases occurs.

\section{References:-}

1. Omar Faiz, David Moffat, The venous and lymphatic drainage of the upper limb and the breast, chapter 29, Anatomy at a Glance, $1^{\text {st }}$ edition, Blackwell Science Ltd, 2002, Italy, p: 69.

2. Richard Sainsbury, The breast, chapter 53, Bailey and Loves, short practice of surgery, $26^{\text {th }}$ edition, CRC Press, Taylor and Francis Group, 2013, London, p: 798.

3. J.Michael Dixon, The breast, chapter 19 , principles and practice of surgery, $6^{\text {th }}$ edition, Churchill livingstone Elsevier, 2012, China, p: 323.

4. Sriram Bhat M, Breast, chapter 8 , SRBS, Manual of surgery, $4^{\text {th }}$ edition, Jaype brothers medical publishers (p) LTD, 2013, Newdelhy; p: 544.

5. GreydanusDE, Matytsina L, Gains M. Breast disorders in children and adolescents. Prim Care2006; 33: 455502.

6. CoffinCM. The breast. In: Stocker JT, Dehner LP, eds. Pediatric pathology. 2nd ed. Philadelphia, Pa: Lippincott Williams \& Wilkins, 2002; 993-1015.

7. PettinatoG, Manivel JC, Kelly DR, Wold LE, Dehner LP. Lesions of the breast in children exclusive of typical fibroadenoma and gynecomastia: a clinicopathologic study of 113 cases. Pathol Annu1989; 24(pt 2): 296-328

8. BockK, Duda VF, Hadji P, et al. Pathologic breast conditions in childhood and adolescence: evaluation by sonographic diagnosis. J Ultrasound Med2005; 24: 1347-1354.

9. WelchST, Babcock DS, Ballard ET. Sonography of pediatric male breast masses: gynecomastia and beyond. Pediatr Radiol2004; 34: 952-957.

10. O’HarePM, Frieden IJ. Virginal breast hypertrophy. Pediatr Dermatol2000; 17: 277-281.

11. Richrd S.Snell, the upper limb, chapter 9 , clinical anatomy by regions, $8^{\text {th }}$ edition, Wolters Kluwer, Lippincott Williams \& wikins, 2007; p: 431. 
12. Monica Morrow, The Evaluation of Common Breast Problems, Am Fam Physician. 2000 Apr 15;61 (8) : 23712378.

13. Morrow M, Wong S, Venta L. The evaluation of breast masses in women younger than forty years of age. Surgery. 1998;124:634-40.

14. Ciatto S, Cariaggi P, Bulgaresi P. The value of routine cytologic examination of breast cyst fluids. Acta Cytol. 1987;31:301-4.

15. Hamed S, Coady A, Chaudary MA, Fentiman IS. Follow-up of patients with aspirated breast cysts is necessary. Arch Surg. 1989;124:253-5.

16. Morrow M, Schmidt RA, Bucci C. Breast conservation for mammographically occult carcinoma. Ann Surg. 1998;227:502-6.

17. American College of Radiology. Standard for the performance of diagnostic mammography. Retrieved January 20, 2000, from the World Wide Web:

http://www.acr.org/departments/stand_accred/standards/html_standards/html_files/dig/diag_mammo.html.

18. Morrow M, Schmidt R, Hassett C. Patient selection for breast conservation therapy with magnification mammography. Surgery. 1995;118:621-6.

19. Hollingsworth AB, Taylor LD, Rhodes DC. Establishing a histologic basis for false-negative mammograms. Am J Surg. 1993;166:643-7.

20. Edeiken S. Mammography and palpable cancer of the breast.Cancer. 1988;61:263-5.

21. Qinghua Min, Kangwei Shao, Lulan Zhai, Wei Liu, Caisong Zhu, Lixin Yuan and Jun Yang, Differential diagnosis of benign and malignant breast masses using diffusion-weighted magnetic resonance imaging, World Journal of Surgical Oncology, 2015, 13:32, DOI: 10.1186/s12957-014-0431-3.

22. Ays, egül Özdemir, MD, Hakan Özdemir, MD, Is, ,1 Maral, MD, Öznur Konus,, MD, Seçil Yücel, MD, Sedat Is , $1 \mathrm{k}, \mathrm{MD}$, Differential Diagnosis of Solid Breast Lesions Contribution of Doppler Studies to Mammography and Gray Scale Imaging, J Ultrasound Med 20:1091-1101, 2001 • 0278-4297@ 2001 by the American Institute of Ultrasound in Medicine. 